Case Reports in
Gastroenterology
Case Rep Gastroenterol 2021;15:41-46

DOI: 10.1159/000510934

Published online: January 21, 2021

(C) 2021 The Author(s)

Published by S. Karger AG, Basel

This article is licensed under the Creative Commons Attribution-NonCommercial 4.0 International License (CC BY-NC) (http://www.karger.com/Services/OpenAccessLicense). Usage and distribution for commercial purposes requires written permission.

\title{
Colorectal Metastasis from Ovarian Neoplasm Mimicking Primary Colon Cancer
}

\author{
Anum Aqsa $^{\mathrm{a}}$ Sami Droubi $^{\mathrm{a}}$ Shivantha Amarnath ${ }^{\mathrm{a}}$ Fady Haddad $^{\mathrm{b}}$ \\ Liliane Deeb $^{\mathrm{b}}$ \\ aDepartment of Internal Medicine, Staten Island University Hospital, New York, NY, USA; \\ ${ }^{b}$ Department of Gastroenterology, Staten Island University Hospital, New York, NY, USA
}

\section{Keywords}

Colorectal metastasis - Primary ovarian neoplasm

\begin{abstract}
Metastasis to the colon from another primary internal malignancy is an untypical and a seldom reported entity. Direct visualization during colonoscopy is considered the gold standard of diagnosis. Pathologic diagnosis with immunohistochemical staining is essential to differentiate primary colorectal malignancy from secondary metastasis to the colon. We, hereby, present a case of a 53-year-old female status-post resection of left-sided papillary serous ovarian neoplasm who presented 2 years later with a single rectosigmoid intraluminal ulcerative mass imitating a primary colon cancer. Biopsies of the mass were consistent with metastasis from her primary ovarian carcinoma. We believe this case is unique because of the rarity of ovarian cancer metastasizing to the colon intraluminally rather than through direct locoregional invasion. Furthermore, it highlights the importance of considering secondary metastasis in patients with previous history of another primary internal malignancy.
\end{abstract}




\section{Case Reports in Gastroenterology}

Case Rep Gastroenterol 2021;15:41-46

\begin{tabular}{l|c|c|}
\hline DOI: 10.1159/000510934 & $\odot 2021$ The Author(s). Published by S. Karger AG, Basel
\end{tabular} www.karger.com/crg

Aqsa et al.: Colorectal Metastasis from Ovarian Neoplasm Mimicking Primary Colon Cancer

\section{Introduction}

Colorectal cancer is the third most frequent malignancy worldwide. Colorectal metastasis, on the other hand, is a rare entity comprising $1 \%$ of total colorectal malignancies [1]. Although secondary colorectal metastasis is infrequent, increased incidence has been observed lately. This is likely due to the increased awareness of physicians as well as the wide use of immunohistochemical staining in the diagnosis of colonic malignancies [2].

The source of colorectal metastasis could be a primary neoplasm of lung, genitourinary system, breast, prostate, kidney, gastrointestinal or hepatobiliary system $[3,4]$. Ovarian origin represents around $6 \%$ of colonic metastases according to one autopsy series [5]. Typically, secondary metastasis to colon from ovarian cancer occurs by peritoneal seeding and/or direct invasion through the colonic wall. We, hereby, discuss a case of secondary metastasis to the colon from a primary ovarian carcinoma in the form of a mass mimicking a primary colon cancer [5]. Interestingly, there was no disease dissemination in the pelvic cavity but solely inside the lumen of the colon, suggestive of a hematogenous or lymphatic spread rather than the typical direct invasion of a metastatic ovarian cancer.

\section{Case Presentation}

A 53-year-old female was diagnosed with a large left pelvic mass and mild bilateral hydronephrosis revealed on a computed tomography (CT) of the abdomen and pelvis complemented with a transvaginal ultrasound. She underwent exploratory laparotomy with total abdominal hysterectomy and bilateral salphingo-oophorectomy, with regional lymph node resection and omentectomy. Tissue diagnosis was consistent with high-grade papillary serous carcinoma of the left ovary (breast cancer type 1 susceptibility protein [BRCA] negative). The pathological examination of the specimen and operative findings were consistent with stage T1C, N0 (tumor confined to the ovary with positive peritoneal washing and absent lymph nodes involvement) and AJCC (American Joint Committee on Cancer) stage 1C. The patient received adjuvant chemotherapy, a total of six cycles of carboplatin and paclitaxel on weekly basis.

For a period of 2 years thereafter, periodic monitoring was always consistent with no evidence of recurrent disease. Then, on a surveillance checkup, a repeat laboratory testing revealed an increased CA 125 level (carbohydrate antigen). This was followed by a positron emission tomography-CT (PET-CT) from skull to thigh which disclosed focal FDG (fluorodeoxyglucose) uptake (13.3 SUV) in the high rectum measuring $3.3 \mathrm{~cm}$ on emission images and co-registering with suspicious wall-thickening on a contrast CT scan. No other sites of potentially suspicious abnormal FDG uptake were seen on the PET-CT. At this point in time, the patient did not exhibit any clinical manifestations, namely no rectal bleeding, abdominal pain or weight loss.

Colonoscopy showed a $5 \times 7 \mathrm{~cm}$ submucosal mass that was $25 \mathrm{~cm}$ from the anal verge, with overlying ulcerations suggestive of a primary colon cancer versus a metastatic lesion (Fig. 1). Multiple biopsies were obtained from the ulcerated rectosigmoid mass to disclose carcinoma cells with psammoma bodies consistent with metastatic ovarian carcinoma. The patient underwent robot-assisted low anterior resection of the rectosigmoid in which dense adhesions of the lesion to lateral pelvic wall were seen. Histopathology revealed lymphovascular invasion without serosal involvement. Three of the six regional lymph nodes had

\section{Karger'=}




\section{Case Reports in Gastroenterology}

Case Rep Gastroenterol 2021;15:41-46

DOI: 10.1159/000510934

(c) 2021 The Author(s). Published by S. Karger AG, Basel www.karger.com/crg

Aqsa et al.: Colorectal Metastasis from Ovarian Neoplasm Mimicking Primary Colon Cancer

evidence of metastatic ovarian malignancy. The surgical resection margins and donut specimen from anastomotic site were clear from any neoplastic process. The immunohistological staining was positive for carbohydrate antigen 125 (CA), paired box protein 8 (PAX), tumor protein (P53), cytokeratin (CK) 7, negative for CK20 and platinum sensitive (Fig. 2). The patient, then, underwent six cycles of adjuvant chemotherapy on a weekly basis with cisplatin and paclitaxel for recurrent ovarian carcinoma with colorectal metastasis. The treatment was consolidated by a maintenance chemotherapy course of niraparib which was well-tolerated too. The patient was then followed up every 2 months until PET-CT scan after chemotherapy did not show any signs of tumor activity.

\section{Discussion}

Secondary metastasis to colon can occur either via direct invasion and extension from a malignancy in neighboring organs through peritoneal seeding, or as intraluminal/intramural recurrence via hematogenous or lymphatic spread [1]. Hematogenous and lymphatic spread is observed with secondary metastasis from primary breast and lung cancers and melanomas [2]. Metastasis by peritoneal and serosal pathway is the common route of ovarian carcinoma spread to colon [6]. The unusual presentation of luminal and mural involvement in our case in the absence of locoregional invasion suggests a hematogenous and/or lymphatic spread of our patient's ovarian cancer to her colon $[7,8]$.

Rectosigmoid and descending colon is the most common site of metastasis from ovarian carcinoma followed by ascending colon [5-9]. Gastrointestinal tract metastasis from ovarian cancer can present 1-22 years after the initial diagnosis of ovarian cancer, with an average of 9 years [2]. The extent of clinical presentation is broad and is similar to the spectrum of presentation for primary colorectal malignancy. Patients with colorectal metastasis often are asymptomatic as we had observed in our case. Absence of symptoms can lead to delayed diagnosis. Presentations include bowel obstruction, anemia, perforation, vague abdominal discomfort and rarely bowel intussusception or fistulization.

Gross endoscopic appearance of colonic metastatic tumors can be either protruding or ulcerative. In most cases, it is often difficult to differentiate primary colonic adenocarcinoma from a metastatic lesion. Diagnostic yield is increased with adjunct diagnostic imaging modalities like ultrasound, CT, magnetic resonance imaging (MRI) of abdomen and pelvis, or positron emission tomography (PET scan). Immunohistochemistry plays a vital role in the realms of diagnosis and differentiation of primary colorectal cancer from metastasis. Tumor markers including carcinoembryonic antigen (CEA) and carbohydrate antigens (CA 125 and CA 19-9) could offer an additional role in distinguishing a primary colon cancer from an ovarian metastasis, as well as to monitor response to therapy $[10,11]$.

Definite management of secondary colorectal metastasis from ovaries is complete resection of the tumor burden along with chemotherapy or radiotherapy. Colorectal resection should involve a palpably negative longitudinal margin of at least $5 \mathrm{~cm}$ of intestine with a wedge of the mesentery, including paracolic and intermediate lymph nodes. If the mesenteric lymph nodes are palpable, proximal segment of mesentery should also be removed [12]. Serial debulking procedures are often required in case of disseminated malignancy to ensure complete removal and improve survival. Overall survival of secondary colorectal cancer depends on the type of the primary malignancy, time of diagnosis of metastasis, age of the patient and

\section{Karger's}




\section{Case Reports in Gastroenterology}

\begin{tabular}{l|l}
\hline Case Rep Gastroenterol 2021;15:41-46 \\
\hline DOI: 10.1159/000510934 & $\begin{array}{l}\text { @ 2021 The Author(s). Published by S. Karger AG, Basel } \\
\text { www.karger.com/crg }\end{array}$ \\
\hline
\end{tabular}

Aqsa et al.: Colorectal Metastasis from Ovarian Neoplasm Mimicking Primary Colon Cancer

follow-up [13]. It can be improved with timely primary site control and management of distant metastasis.

In conclusion, secondary colon metastasis is exceptional. The case we presented was unusual considering that the primary source was ovarian carcinoma and since its pattern of spread was luminal without locoregional involvement. Distinction between primary colon carcinoma and secondary metastasis can be challenging. Having a high level of suspicion for colon metastasis is important in patients with a history of a primary neoplasm presenting with new intestinal symptoms or new incidental finding of colon tumor.

\section{Statement of Ethics}

Informed written consent was taken from the patient and the family members to publish this case report including images. Ethical approval was granted from the Staten Island University Hospital to undertake this study. This report followed guidelines to be HIPAA compliant. The study adhered to the tenets of the World Medical Association Declaration of Helsinki.

\section{Conflict of Interest Statement}

The authors have no conflicts of interest to disclose.

\section{Financial Sources}

No funding to declare.

\section{Author Contributions}

Anum Aqsa and Sami Droubi: literature review, writing manuscript. Shivantha Amarnath: final review of the manuscript. Fady Haddad and Liliane Deeb: supervision. The final version of the manuscript was read and approved by all authors.

\section{References}

1 Caramella E, Bruneton JN, Roux P, Aubanel D, Lecomte P. Metastases of the digestive tract. Report of 77 cases and review of the literature. Eur J Radiol. 1983 Nov;3(4):331-8.

2 Galanopoulos M, Gkeros F, Liatsos C, Pontas C, Papaefthymiou A, Viazis N, et al. Secondary metastatic lesions to colon and rectum. Ann Gastroenterol. 2018 May-Jun;31(3):282-7.

3 Falco G, Mele S, Zizzo M, Di Grezia G, Cecinato P, Besutti G, et al. Colonic metastasis from breast carcinoma detection by CESM and PET/CT: A case report. Medicine (Baltimore). 2018 May;97(21):e10888.

4 Smith HJ, Vlasak MG. Metastasis to the colon from bronchogenic carcinoma. Gastrointest Radiol. 1978 Feb;2(4):393-6.

5 Shibahara K, Endo K, Ikeda T, Sakata H, Sadanaga N, Morita M, et al. Colon metastasis 20 years after the removal of ovarian cancer: report of a case. Surg Today. 2009;39(2):153-6.

6 Mourra N, Jouret-Mourin A, Lazure T, Audard V, Albiges L, Malbois M, et al. Metastatic tumors to the colon and rectum: a multi-institutional study. Arch Pathol Lab Med. 2012 Nov;136(11):1397-401.

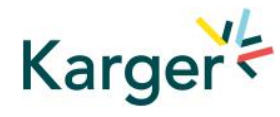




\section{Case Reports in Gastroenterology}

\begin{tabular}{l|l}
\hline DOI: 10.1159/000510934 & $\begin{array}{l}\text { @ } 2021 \text { The Author(s). Published by S. Karger AG, Basel } \\
\text { www.karger.com/crg }\end{array}$ \\
\hline
\end{tabular}

Aqsa et al.: Colorectal Metastasis from Ovarian Neoplasm Mimicking Primary Colon Cancer

7 El Mehdi T, Essadi I, M'rabti H, Errihani H. Rare recurrence of a rare ovarian stromal tumor with luteinized cells: a case report. J Med Case Reports. 2011 Aug;5(1):350.

8 Lengyel E. Ovarian cancer development and metastasis. Am J Pathol. 2010 Sep;177(3):1053-64.

9 Wu PC, Lang JH, Huang RL, Liu J, Tang MY, Lian LJ. Intestinal metastasis and operation in ovarian cancer: a report on 62 cases. Baillieres Clin Obstet Gynaecol. 1989 Mar;3(1):95-108.

10 Yamamoto H, Miyake Y, Noura S, Ogawa M, Yasui M, Ikenaga M, et al. [Tumor markers for colorectal cancer]. Gan To Kagaku Ryoho. 2001 Sep;28(9):1299-305.

11 Liu Z, Zhang Y, Niu Y, Li K, Liu X, Chen H, et al. A systematic review and meta-analysis of diagnostic and prognostic serum biomarkers of colorectal cancer. PLoS One. 2014 Aug;9(8):e103910.

12 O'Hanlan KA, Kargas S, Schreiber M, Burrs D, Mallipeddi P, Longacre T, et al. Ovarian carcinoma metastases to gastrointestinal tract appear to spread like colon carcinoma: implications for surgical resection. Gynecol Oncol. 1995 Nov;59(2):200-6.

13 Gillette-Cloven N, Burger RA, Monk BJ, McMeekin DS, Vasilev S, DiSaia PJ, et al. Bowel resection at the time of primary cytoreduction for epithelial ovarian cancer. J Am Coll Surg. 2001 Dec;193(6):626-32.

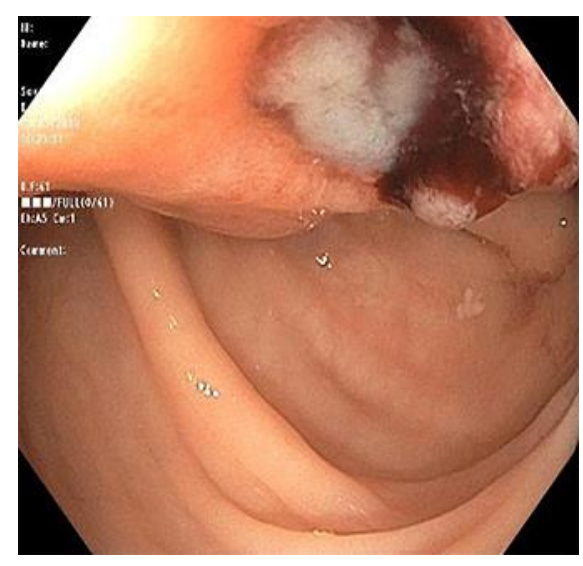

Fig. 1. Colonoscopy image depicting ulcerated rectosigmoid lesion. 

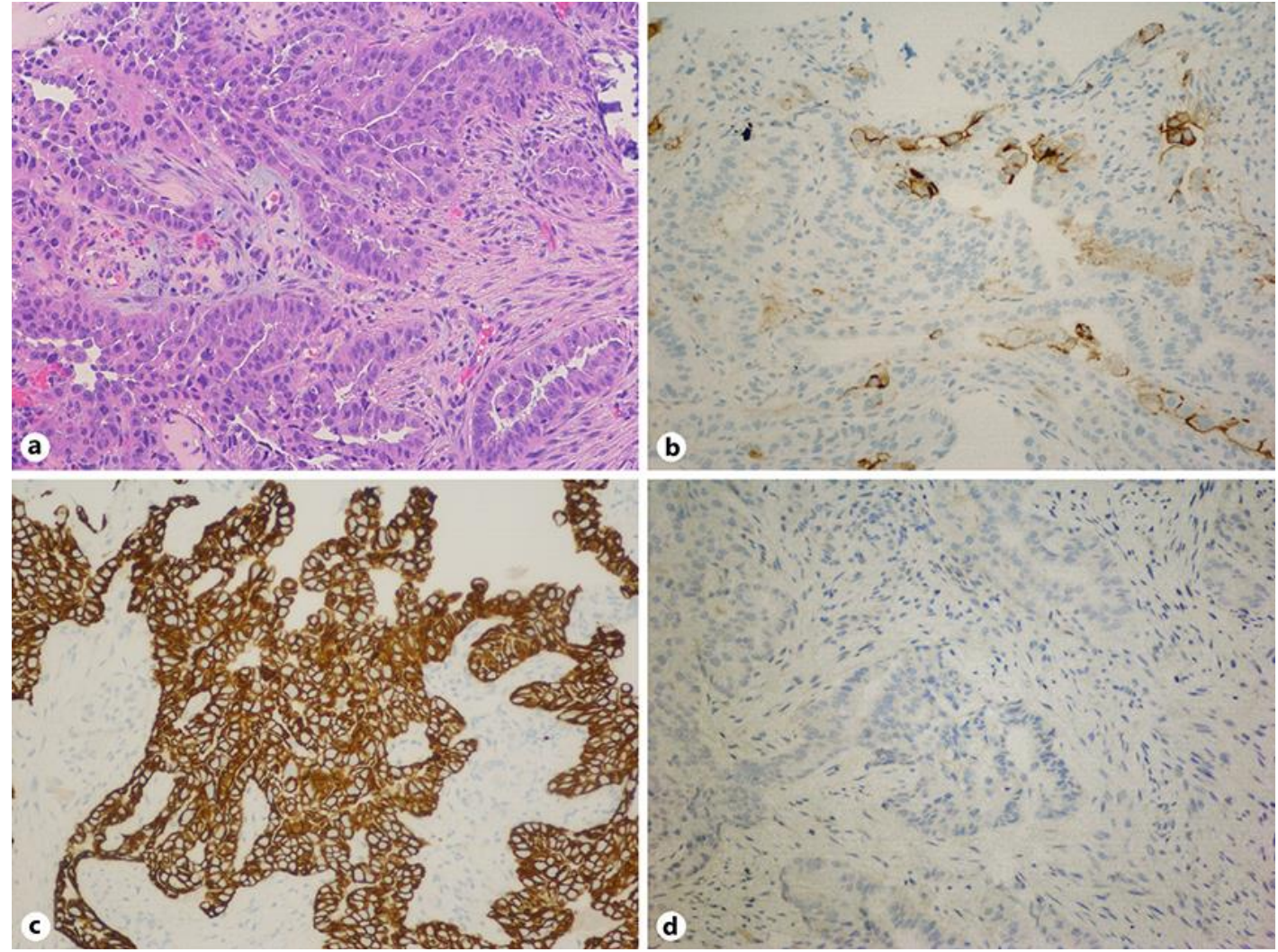

Fig. 2. H\&E stain (a) showing psammoma bodies, involving fragments of colonic mucosa, favoring metastatic primary ovarian cancer. Immunohistology stain positive for CA-125 (carbohydrate antigen) (b), CK7 (cytokeratin) (c) and negative for CK-20 (d), confirming the diagnosis of primary ovarian cancer. 